\title{
Efficacy of a Novel Herbal Formulation (F2) on the Management of Obesity: In Vitro and In Vivo Study
}

\author{
Prakash Raj Pandeya $\mathbb{D}^{1},{ }^{1}$ Ramakanta Lamichhane $\mathbb{( D},{ }^{1}$ Kyung-Hee Lee $\mathbb{D}{ }^{1}$ \\ Gopal Lamichhane $\mathbb{D}^{1},{ }^{1}$ Se-Gun Kim $\mathbb{D}^{2},{ }^{2}$ and Hyun-Ju Jung $\mathbb{D}^{1}$ \\ ${ }^{1}$ Department of Oriental Pharmacy and Wonkwang-Oriental Medicines Research Institute, Wonkwang University, \\ Sinyong-Dong, Iksan 570-749, Republic of Korea \\ ${ }^{2}$ Department of Agricultural Biology, National Academy of Agricultural Science, Rural Development Administration, \\ Wanju 566-851, Republic of Korea
}

Correspondence should be addressed to Hyun-Ju Jung; hyun104@wku.ac.kr

Received 11 August 2020; Revised 7 January 2021; Accepted 28 January 2021; Published 8 February 2021

Academic Editor: Weicheng $\mathrm{Hu}$

Copyright (C) 2021 Prakash Raj Pandeya et al. This is an open access article distributed under the Creative Commons Attribution License, which permits unrestricted use, distribution, and reproduction in any medium, provided the original work is properly cited.

\begin{abstract}
Background. Currently, obesity and its comorbidities have become a serious threat to human health necessitating urgent development of safe and effective therapy for their management. Materials and Methods. In this research, a novel polyherbal formulation (F2) was prepared by mixing specific proportions of royal jelly and lemon juice with ethanol extracts of Orostachys japonicus, Rhus verniciflua, and Geranium thunbergii. The antioxidant activity was assessed using DPPH and ABTS assay methods. The antiobesity potential of the F2 was assessed in vitro using 3T3-L1 fibroblast and in vivo using a high-fat diet (HFD) fed C57BL/6J mice model. F2 was administered in mice at the dose of $23 \mathrm{mg} / \mathrm{kg}$ and $46 \mathrm{mg} / \mathrm{kg}$, twice daily by oral gavage. A wellaccepted antiobesity agent, Garcinia cambogia (GC), at $200 \mathrm{mg} / \mathrm{kg}$ was used as a positive control. Results. F2 was observed to exhibit synergistic antiadipogenic activity in 3T3-L1 cells. This inhibition was reinforced by the downregulation of specific adipogenic transcription factors. Furthermore, F2 was also found to reduce mice body weight gain, food efficiency ratio, fasting blood glucose level, fat deposition into the liver, and mass of white adipose tissue. F2 also played a role in the excretion of fat consumed by the mice. For most of the assays performed, the F2 $(46 \mathrm{mg} / \mathrm{kg}$ ) was comparable to the positive control GC (200 mg/ $\mathrm{kg}$ ). In addition, potential and synergistic antioxidant activity was observed on F2. Conclusion. The results revealed that the formulation F2 exhibited potential antiobesity activity through the inhibition of adipocyte differentiation, dietary fat absorption, and reduction of free fatty acids deposition in tissues.
\end{abstract}

\section{Introduction}

According to World Health Organization (WHO), obesity is the accumulation of abnormal or excessive fat into the body to the extent that may impair health condition. Based on body mass index (BMI), an adult is considered overweight if the BMI is greater than or equal to 25 and becomes obese when BMI reaches more than 30 [1]. About $40 \%$ of the world's current population is suffering from overweight or obesity and is still in an increasing pattern [2]. Besides, childhood obesity is becoming a serious issue in the present time. WHO reports say 42 million children under 5 years of age were overweight or obese in 2016 [3]. Obesity is characterized by the increased size of adipocytes due to accumulation of lipids (hypertrophy), and/or increased number of adipocytes due to over-differentiation of preadipocytes into adipocytes (hyperplasia) under the influence of appropriate nutrition and hormonal release [4-6]. Obesity is associated with multiple metabolic disorders such as type 2 diabetes, cardiovascular diseases, fatty liver disease, mental disorders, and even certain cancers. Primarily, obesity may be controlled or prevented by nonpharmaceutical practices such as taking of restricted-calorie diet, physical exercise, and changing eating behavior. If the nonpharmaceutical 
practice does not give proper results, pharmaceutical interventions may be suggested [7]. Due to having more adverse effects, high cost, and a physical dependency of the pharmaceutical medicines, the uses of herbal medicine are increasing globally for the management of overweight and obesity [8]. Still, individual plants or phytochemical constituents may not be sufficient to achieve the desired therapeutic effect. A combination of multiple herbs may give a better therapeutic effect with reduced toxicity [9].

Orostachys japonicus (OJ) A. Berger (Crassulaceae) is a Korean medicinal plant. Traditionally, OJ has been used in the treatment and/or prevention of gastric ulcers, hepatitis, hemorrhoids, hematemesis, and cancer [10, 11]. The phytochemical composition of OJ includes triterpene, sterols, and flavonoids [11]. Previous studies revealed that OJ has shown potential antioxidant, hypoglycaemic, anticancer, anti-HIV-1 protease, antiulcerogenic, analgesic, immunostimulatory, and hepatoprotective effects [10-12]. Antiadipogenic and antiobesity effects of $\mathrm{OJ}$ were also described previously in various in vitro and in vivo studies $[10,13,14]$.

Rhus verniciflua (RV) Stokes (Anacardiaceae) has been used as a traditional medicine as well as a food additive in eastern Asia [15]. RV can be used as an antiviral, cathartic, diaphoretic, antirheumatic, and sedative agent [16]. Scientific studies revealed that RV and its isolated compounds showed anticancer, anti-inflammatory, antioxidant, antiapoptotic, antirheumatic, antiplatelet, antimutagenic, antifibrogenic, cytoprotective, antidiabetic, and antiobesity activities [15-18]. The antiobesity action of the RV might be due to the presence of active compounds such as lutein and sulfuretin $[15,16]$. Other biologically active compounds isolated from RV are fisetin, fustin, kaempferol, gallic acid, quercetin, and protocatechuic acid [15].

Geranium thunbergii (GT) Sieb. (Geraniaceae) is a perennial plant distributed in China, Japan, and Korea [19]. Traditionally, the whole plant has been used for diarrhea, constipation, skin diseases, and stomach ulcer. According to previous scientific reports, GT showed antimutagenic, antioxidant, anti-inflammatory, antiobesity, and BACE1 (Betasite APP Cleaving Enzyme 1) inhibitory activities [19, 20]. Chlorogenic acid, a major phenolic compound in GT, showed antiobesity activity in high-fat diet-induced obese mice [21].

The antiadipogenic and/or antiobesity activities of O. japonicus, R. verniciflua, G. thunbergii, and royal jelly (RJ) were individually evaluated on the cell line, animal model, or clinical trials [10, 14, 15, 19, 22-27]. In our previous studies, we found evidence that GT, RV, OJ, and RJ showed potential antiadipogenic and/or antiobesity activity in 3T3-L1 adipocytes or Sprague-Dawley Rats [13, 16, 28-31]. Therefore, our objective was to develop an effective antiobesity herbal formulation using these natural medicines. We prepared several formulations by mixing these natural components in various ratios and prestudied their lipid inhibition activity in 3T3-L1 adipocytes. The formulation F2 was found to be most active among the prepared formulations and thus selected for further study using obese mice. In the present study, we have evaluated the antiadipogenic and antiobesity activities of F2 using 3T3-L1 adipocytes and high-fat diet (HFD) fed
C57BL/6J mice. Furthermore, synergy on formulation F2 was evaluated.

\section{Materials and Methods}

2.1. Extraction of F2 Ingredients. Orostachys japonicus (OJaerial parts), Rhus verniciflua (RV-stem wood), and Geranium thunbergii (GT-aerial parts) were purchased from a medical herb store, Begjangseng (Iksan, Korea), and were identified by Professor Hyun-Ju Jung, Wonkwang University. Royal jelly (RJ) was obtained from Yeoju Honey Park, Korea, and was stored at $-20^{\circ} \mathrm{C}$ until use. Lemon was purchased from a local market. The plant samples were separately extracted by reflux ing at $90^{\circ} \mathrm{C}$ temperature for $3 \mathrm{~h}$ using ethanol solvent. The same extraction procedure was applied for plant ingredients. Before mixing the ingredients for F2, all the plant extracts, royal jelly, and lemon juice were separately dried using a freeze dryer (IIShin Lab Co., Ltd., Korea).

2.2. Preparation of $F 2$. The formulation $\mathrm{F} 2$ was prepared by mixing a specific proportion of ethanol extracts of OJ, RV, and GT along with a trace amount of freeze-dried royal jelly and lemon juice. The ratios of each component of F2 are indicated in Table 1.

2.3. Phytochemical Analysis of F2 Using UPLC. An ultraperformance liquid chromatography (UPLC) system (Agilent Technologies, Santa Clara, CA, US) consisting of a G4220A 1290 Infinity Binary pump, a G4226A 1290 autosampler, and a G4242A 1290 DAD detector was used for the analysis of F2. The Halo C18 RP-amide column $(150 \mathrm{~mm} \times 2.1 \mathrm{~mm}, 2 \mu \mathrm{m}$ particle sizes $)$ was used for the study. A suitable chromatographic solvent system consisting of (A) acetonitrile and (B) $0.5 \%$ phosphoric acid in water was optimized and performed in a gradient flow as follows: (A)/ $(B)=1 / 99 \quad(0 \mathrm{~min}) \longrightarrow(\mathrm{A}) /(\mathrm{B})=16 / 84 \quad(30 \mathrm{~min}$; held for $20 \mathrm{~min}$ ). The operating conditions were as follows: flow rate, $2 \mathrm{~mL} / \mathrm{min}$; sample injection volume, $5 \mu \mathrm{L}$; column temperature, $40^{\circ} \mathrm{C}$; detection wavelength, 210 and $250 \mathrm{~nm}$. Five standards, including astragalin (Kaempferol-3-O-glucoside), fustin, fisetin, sulfuretin, and ellagic acid, were used as reference compounds for the quantification of F2. For UPLC analysis, F2 and the herb ingredients were prepared at a concentration of $20 \mathrm{mg} / \mathrm{mL}$, whereas each of the standard compounds was prepared at $1 \mathrm{mg} / \mathrm{mL}$ in methanol. All the solutions were filtered through $0.2 \mu \mathrm{m}$ PTFE hydrophilic syringe filters before injection.

2.4. In Vitro Antioxidant Assays. Antioxidant activity of the F2 and its ingredients was assayed by DPPH and ABTS radical scavenging activity assays. The DPPH (1,1-diphenyl2-picrylhydrazyl) and ABTS (2,2'-azino-bis(3-ethylbenzothiazoline-6-sulfonic acid)) radical scavenging activities were assessed by using the methods described by Jeong et al. [32] and Choi et al. [33], respectively. The antioxidant activities were calculated using the following equation: 
TABle 1: Composition of F2.

\begin{tabular}{lcc}
\hline Ingredients & Part used & Parts by weight (\%,w/w) \\
\hline Orostachys japonicus (OJ) & Aerial parts & $400(49.88 \%)$ \\
Rhus verniciflua (RV) & Stem wood & $300(37.41 \%)$ \\
Geranium thunbergii & Aerial parts & $100(12.47 \%)$ \\
(GT) & Whole jelly & $1(0.12 \%)$ \\
Royal jelly (RJ) & Juice & $1(0.12 \%)$ \\
Citrus limon (Lemon) & & \\
\hline
\end{tabular}

$$
\text { scavenging activity }(\%)=\left[1-\left(\frac{\mathrm{Abs}_{\text {sample }}}{\mathrm{Abs}_{\text {control }}}\right)\right] \times 100 \text {. }
$$

The results were expressed as $\mathrm{IC}_{50}$ (quantity of antioxidants necessary to reduce free radicals by $50 \%$ concentration). Calculations were performed using a logarithmic regression curve plotted between radical scavenging activity and treated concentrations.

2.5. Cell Culture and Differentiation of 3T3-L1 Adipocytes. 3T3-L1 fibroblast cells (ATCC ${ }^{\circledR}$ CL-173 ${ }^{\mathrm{TM}}$ ) were purchased from American Type Culture Collection (ATCC). The culture and differentiations of 3T3-L1 adipocytes were performed as the method described in the previous publication [30]. Briefly, the cells were grown and passaged in Dulbecco's modified eagle medium (DMEM) containing $10 \%$ newborn calf serum (NCS) and $1 \%$ penicillin/streptomycin in a humidified atmosphere of $5 \% \mathrm{CO}_{2}$ at $37^{\circ} \mathrm{C}$. The differentiation of 3T3-L1 preadipocytes was induced by treatment of the differentiating media after two days of the confluency. The differentiating media (MDI) consist of $0.5 \mathrm{mM}$ methylisobutylxanthine (IBMX), $1 \mu \mathrm{M}$ dexamethasone, and $5 \mu \mathrm{g} / \mathrm{mL}$ insulin in DMEM containing $10 \%$ fetal bovine serum (FBS). The samples were treated by mixing with MDI media. For the assessment of cell viability, the cells were treated with 5 to $80 \mu \mathrm{g} / \mathrm{mL}$ of F2 mixing with MDI media and allowed to incubate for 8 days with changing media in alternative days. The MTT assay was done to determine cell viability on the $8^{\text {th }}$ day of sample treatment. The safe concentrations were treated to measure antiadipogenic activity. The synergistic antiadipogenic effect of the formulation F2 was determined by treating all the ingredients in an equivalent concentration present in $60 \mu \mathrm{g} /$ $\mathrm{mL}$ of F2. On the $8^{\text {th }}$ day of cell treatment, lipid contents accumulated in adipocytes were assessed by ORO staining.

2.6. RNA Extraction and Real-Time PCR Analysis. The RNA extraction, cDNA synthesis, and real-time PCR analysis were performed on 3T3-L1 adipocytes according to the previously described methods [30]. The total RNAs from the F2 treated and untreated 3T3-L1 adipocytes were extracted separately with QIAzol lysis reagent (Maryland, USA) according to the manufacturer's protocol. The cDNA was synthesized from RNA using a High-capacity RNA-tocDNA kit (Applied Biosystems, UK) on Takara PCR Thermal Cycler (Takara, Japan). The gene expression levels were analyzed by quantitative real-time (RT) PCR. The cDNA aliquots were amplified on a StepOnePlus Real-Time
PCR system from Applied Biosystems Inc. (Marsiling Industrial Estate Road 3, Singapore) using the Power SYBRGreen PCR Master Mix (Applied Biosystems, UK) in a final volume of $20 \mu \mathrm{L}$. The primers used in the experiments were synthesized by Cosmo Genetech Co. Ltd. (South Korea) and are shown in Table 2 . The $\beta$-actin was used as a reference gene. The relative mRNA expression levels were calculated using the $\Delta \Delta \mathrm{Ct}$ method [34].

\subsection{Experimental Animals and Grouping. Male C57BL/6J} mice were supplied by Central Lab. Animal Inc., Seoul, Korea. The mice were housed and allowed free access to feed and tap water under controlled and pathogen-free conditions (room temperature: $24 \pm 1^{\circ} \mathrm{C}$, relative humidity: 50-60\%, light cycle: 7:00-19:00). The animal experiment was approved by the Wonkwang University Animal Ethics Committee (Approval No.: WKU19-78). The animals were handled in accordance with the "Guide for Care and Use of Laboratory Animals" issued by the National Institutes of Health. The mice were acclimatized to their environment for 1 week before the commencement of the experiments. Mice (age 6 weeks) were weighed and randomly divided into five groups each containing five mice. A normal group was fed with the standard chow diet (standard diet: 5L79 Orient Bio Inc., Seongnam, Korea) consisting of $13.67 \%$ fat, $20.1 \%$ protein, and $65.30 \%$ carbohydrate. The remaining four groups were fed with a high-fat diet (Rodent Diet D12451, Research Diets, New Brunswick, NJ, USA) consisting of $45 \%$ fat, $20 \%$ protein, and $35 \%$ carbohydrate. The normal and high-fat diet-fed control (HFD control) groups were treated with vehicle ( $0.2 \%$ carboxymethyl cellulose/PBS) orally. Two groups, F2-23 and F2-46, received F2 at doses of 23 and $46 \mathrm{mg} / \mathrm{kg}$, twice daily, respectively, by oral gavage. A wellaccepted antiobesity agent, Garcinia cambogia (GC), at $200 \mathrm{mg} / \mathrm{kg}$, twice daily, was used as a positive control group. The mice were treated with respective samples from the same day of switching chow diet to HFD and continued for 8 weeks. Body weight and food intake were recorded every week. The food efficiency ratio (FER) was calculated as follows [10]:

$$
\text { FER } \%=\frac{\text { gained body weight }(\mathrm{g}) \times 100}{\text { food intake }(\mathrm{g}) \text { during the experiment period }} .
$$

Mice feces were collected before one day of sacrifice to measure excreted fat. At the end of the experimental period, the mice were fasted for 14 hours prior to sacrifice. Blood glucose was measured before sacrifice by using a one-touch blood glucose monitoring system (CareSens ${ }^{\otimes} \mathrm{N}$, i-sens, Korea). After sacrifice, the weights of epididymal adipose tissue and other organs (liver, kidney, and spleen) were determined and histological evaluation was done for liver and adipose tissue.

2.8. Measurement of Lipid Content in Feces. The lipid excretions into feces were extracted by using the method described by Folch et al. [35] with slight modifications. 
TABLE 2: The primer sequence used for real-time PCR.

\begin{tabular}{lc}
\hline Gene & Primer sequence $\left(5^{\prime}-3^{\prime}\right)$ \\
\hline \multirow{2}{*}{ PPAR $\gamma$} & F: GTG AAG CCC ATC GAG GAC A \\
& R: TGG AGC ACC TTG GCG AAC A \\
C/EBP $\alpha$ & F: GCG GGA ACG CAA CAA CAT C \\
R: & F: GTC ACT GGT CAA CTC CAG CAC \\
& R: CAG CTC ATA GCA CCC TCC TGT G \\
Leptin & F: GCC AGG CTG CCA GAA TTG \\
SREBP 1c & R: CTG CCC CCC AGT TTG ATG \\
& F: GGT TTT GAA CGA CAT CGA AGA \\
LPL & R: CGG GAA GTC ACT GTC TTG GT \\
Fdiponectin & R: TAC AAT CTG GGC TAT GAG ATC AAC \\
& F: GGT GCT GGG AAT TGA ACT CA \\
IL-6 & R: CCT GTT TCC AGG CTT TGG CC \\
& F: AAA TTC GGT ACA TCC TCG ACG G \\
$\beta-A c t i n$ & F: GGA AGG TTC AGG TTG TTT TCT GC \\
& R: GCC GGA CTC ATC GTA CTC C \\
\hline
\end{tabular}

$\operatorname{PPAR} \gamma$, peroxisome proliferator-activated receptor-gamma; $\mathrm{C} / \mathrm{EBP} \alpha$, CAAT/enhancer binding protein alpha; SREBP-1c, sterol response element binding protein-1c; ap2, adipocyte protein 2; LPL, lipoprotein lipase; IL-6, interleukin-6.

Briefly, about $0.5 \mathrm{~g}$ of dry feces was weighed into $15 \mathrm{ml}$ polypropylene conical tubes, $3 \mathrm{~mL}$ of deionized water was added, and kept for 2 hours. Then feces mixture was homogenized by vortexing. Then, the feces sample was mixed with methanol: chloroform $(1: 2, \mathrm{v}: \mathrm{v})$ and vortexed for a few minutes. The sample was then centrifuged at $1600 \mathrm{~g}$ (or $2900 \mathrm{rpm}$ ) for $15 \mathrm{~min}$. The lower lipophilic layer was collected by using a syringe, filtered, and allowed to evaporate and lipid content was measured.

2.9. Measurement of Tissue Weight and Histological Observation. Liver, epididymal white adipose tissues (WAT), kidney, and spleen were isolated from the mice, washed with PBS, and weighed. The liver and WAT were immediately fixed into $10 \%$ neutral formalin solution for 2 days. With alcohol dehydration, the water trapped in the tissues was removed, and then embedding was done using paraffin. All tissues were sliced to $5 \mu \mathrm{m}$ in thickness and stained with H\&E (hematoxylin and eosin). The slides were examined using a light microscope and images were captured on a Canon power shot A640 camera. Images of WAT were analyzed using ImageJ software to evaluate the diameters of the adipocytes.

2.10. Statistical Analysis. Statistically significant differences between groups were determined using a one-way analysis of variance (ANOVA) followed by Dunnett's multiple range tests using GraphPad Prism 4 software. Data are presented as the mean \pm standard deviation (SD). A $p$ value of $<0.05$ was considered to represent statistically significant differences within groups.

\section{Results}

3.1. UPLC Analysis of F2. The typical UPLC chromatograms of the standard mixture, individual plant ingredients, and F2 are shown in Figure 1. Astragalin, fustin, fisetin, and sulfuretin were detected at $210 \mathrm{~nm}$, whereas ellagic acid was detected at $250 \mathrm{~nm}$. The retention times of astragalin, fustin, fisetin, sulfuretin, and ellagic acid were 29.445, 14.792, $33.657,42.800$, and $25.718 \mathrm{~min}$, and the concentrations of these compounds in F2 were 3.64, 35.83, 5.90, 3.22, and $1.82 \mathrm{mg} / \mathrm{g}$, respectively.

3.2. Antioxidant Activity of F2. The antioxidant activities of F2 along with its components in the formulation are expressed in terms of $\mathrm{IC}_{50}$ in Table 3 . The $\mathrm{IC}_{50}$ values are paralleled with standard gallic acid as reference. The result showed that the F2 showed good synergistic antioxidant activity in both DPPH and ABTS antioxidant assay models. The $\mathrm{IC}_{50}$ value of $\mathrm{F} 2$ was found to be $9.52 \mu \mathrm{g} / \mathrm{mL}$, which was less than $\mathrm{OJ}$ and GT in the formulation.

3.3. Effect of F2 on Cell Viability and Lipid Accumulation in 3T3-L1 Adipocytes. The effect of F2 on 3T3-L1 cell viability was determined by MTT assay. The cells were treated with 5 to $80 \mu \mathrm{g} / \mathrm{mL}$ of F2. As shown in Figure 2(a), the F2 was found to be safe below the concentration of $60 \mu \mathrm{g} / \mathrm{mL}$. The safe concentrations of F2 were treated for the assessment of antiadipogenic activity. Lipid accumulations in the adipocytes were visualized and quantified by the ORO staining method. F2 showed a prominent inhibitory activity on the differentiation of 3T3-L1 preadipocytes in a concentrationdependent manner (Figure 2(b)). 20, 40, and $60 \mu \mathrm{g} / \mathrm{mL}$ of F2 were found to inhibit lipid production by $3.63 \pm 6.10$, $13.01 \pm 2.29$, and $29.13 \pm 2.93$ percentage, respectively, relative to blank treated control. The physical conditions of the cells were visualized before and after the ORO staining and were photographed using a light microscope (Figures 2(c) and $2(\mathrm{~d}))$.

3.4. Synergistic Antiadipogenic Effect of F2 on 3T3-L1 Adipocytes. The highest concentration of F2 treated in 3T3L1 adipocytes was $60 \mu \mathrm{g} / \mathrm{mL}$. The amount of individual ingredients presented in that concentration of F2 was calculated according to the ratio of the ingredients in the formulation (Table 1). The amount of GT, RV, OJ, RJ, and lemon equivalent to $60 \mu \mathrm{g} / \mathrm{mL}$ of $\mathrm{F} 2$ was $7.481,22.44,29.93$, 0.074 and $0.074 \mu \mathrm{g} / \mathrm{mL}$, respectively. To evaluate the synergistic activity, $60 \mu \mathrm{g} / \mathrm{mL}$ of F2 and the equivalent concentration of its ingredients were separately treated. The percentage of inhibition of lipid accumulation by F2 and its ingredients is shown in Table 4. From the result, it may be estimated that the theoretical cumulative lipid inhibition would be $5.75 \%$ (measured by calculating the sum of each ingredient's mean inhibition). But the separately treated F2 showed $26.31 \pm 4.73 \%$ of lipid inhibition, indicating the best synergy of its ingredients on formulation F2. 

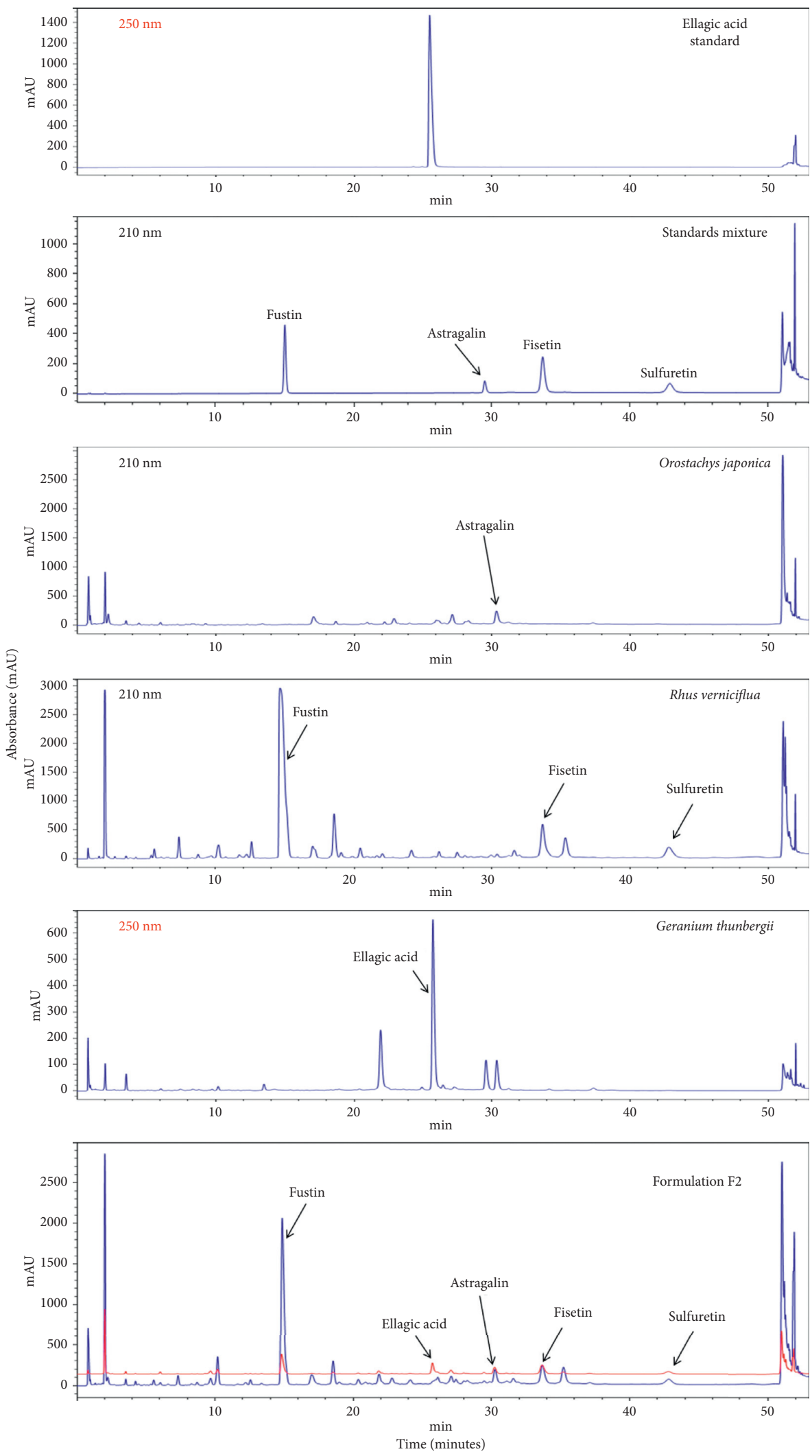

\section{$210 \mathrm{~nm}$
$-250 \mathrm{~nm}$}

FIgURE 1: UPLC chromatograms of ellagic acid, standard mixture (astragalin, fustin, fisetin, sulfuretin), F2 components (Orostachys japonica, Rhus verniciflua, and Geranium thunbergii), and formulation F2. 
TABLE 3: $\mathrm{IC}_{50}$ values for the antioxidant activities of $\mathrm{F} 2$ and its ingredients.

\begin{tabular}{lcc}
\hline Samples & DPPH-IC $_{50}(\mu \mathrm{g} / \mathrm{mL})$ & $\mathrm{ABTS}^{\mathrm{IC}} \mathrm{C}_{50}(\mu \mathrm{g} / \mathrm{mL})$ \\
\hline Formulation F2 & 5.99 & 9.52 \\
Orostachys japonicus & 11.37 & 18.1 \\
Geranium thunbergii & 9.57 & 24.35 \\
Rhus verniciflua & 1.84 & 7.98 \\
Royal jelly & No activity & No activity \\
Citrus limon (lemon) & No activity & No activity \\
Gallic acid & 0.04 & 2.84 \\
\hline
\end{tabular}

The percentage of DPPH and ABTS radical scavenging offered by F2, its components, and standard gallic acid plotted in logarithmic regression curve against concentration and the $\mathrm{IC}_{50}$ was determined by interpolation from the logarithmic regression. The antioxidant activity is expressed in the form of IC $\mathrm{I}_{50}$ value.

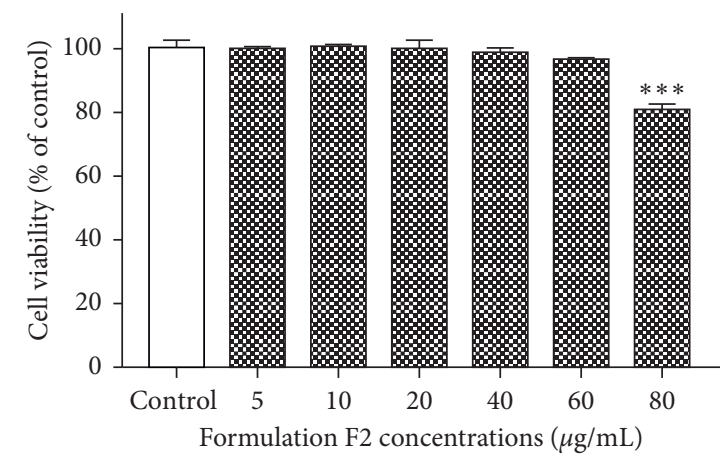

(a)

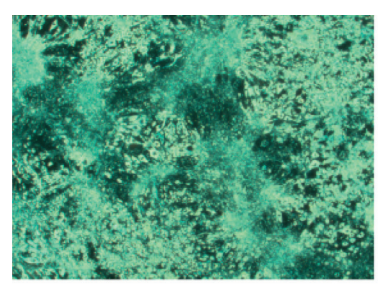

Control

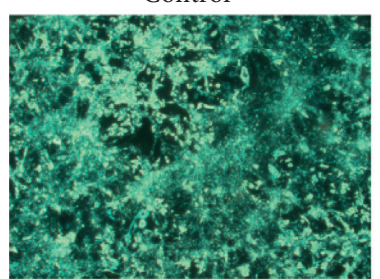

$40 \mu \mathrm{g} / \mathrm{mL}$
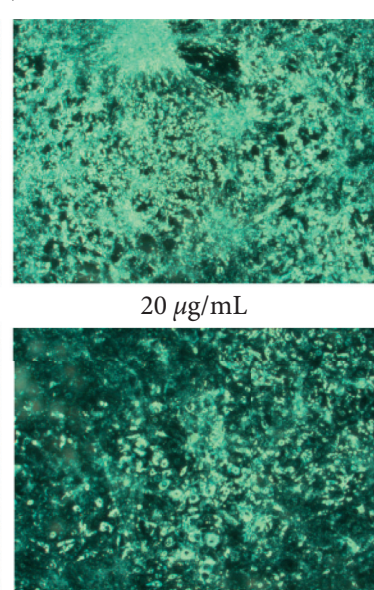

$60 \mu \mathrm{g} / \mathrm{mL}$

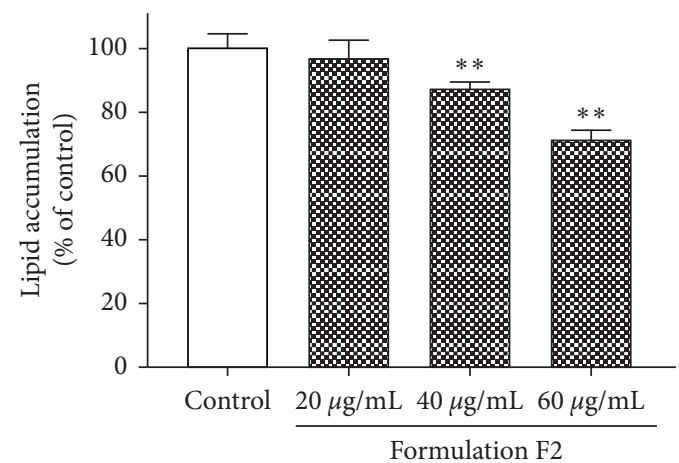

(b)

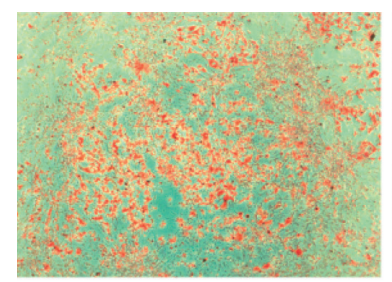

Control

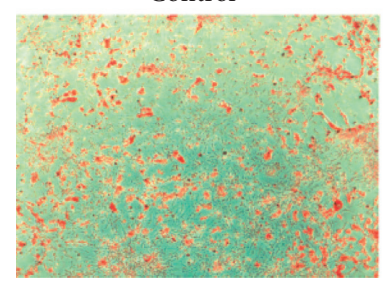

$40 \mu \mathrm{g} / \mathrm{mL}$

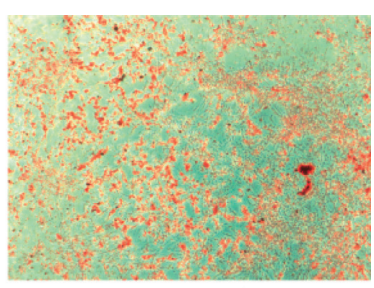

$20 \mu \mathrm{g} / \mathrm{mL}$

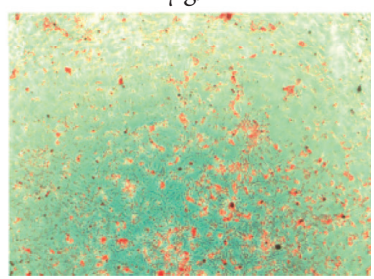

$60 \mu \mathrm{g} / \mathrm{mL}$

(c)

(d)

FIGURE 2: Effect of F2 on cell viability and lipid production in 3T3-L1 adipocytes. The 3T3-L1 preadipocytes were treated with F2 and cell viability (a) was assessed using MTT assay. The amount of lipid accumulation (b) on 3T3-L1 adipocytes was measured by Oil Red O (ORO) assay. The lipid accumulating cells were visualized in 10X magnification before (c) and after (d) the ORO staining. The data shown are presented as means \pm SD of four separate experiments. Statistical significance was calculated using one-way ANOVA followed by Dunnett's multiple comparisons test. $* * p<0.01$ and $* * * p<0.001$ vs. control.

3.5. Effect of F2 on Gene Expression of Adipogenic Transcription Factors in 3T3-L1 Adipocytes. The effect of F2 on the gene expression level of adipogenic transcription factors was examined by real-time PCR. The 3T3-L1 adipocytes were treated with 40 and $60 \mu \mathrm{g} / \mathrm{mL}$ concentrations of F2 and total mRNA was extracted at day 8 of the sample treatment. The mRNA expression level of specific adipogenic markers (PPAR $\gamma, \mathrm{C} / \mathrm{EBP} \alpha$, SREBP-1c, aP2, leptin, LPL, and adiponectin) and inflammatory marker (IL-6) was determined. As shown in Figure 3, the gene expressions of the aforementioned transcription factors and adipogenic markers were markedly downregulated whereas the expression of an IL-6 was upregulated by $\mathrm{F} 2$ in a concentration-dependent manner compared to the control.

3.6. Effect of F2 on Mice Body Weight, Food Intake, and Food Efficiency Ratio during 8 Weeks. The mice were treated for 8 weeks. Mice body weight gaining pattern over the treatment 
TABLE 4: Synergistic action of F2 on fat reduction in 3T3-L1cells.

\begin{tabular}{lcr}
\hline F2 and ingredients & Amount of ingredients in $60 \mu \mathrm{g} / \mathrm{mL}$ of F2 & Lipid inhibition (\%) \\
\hline Control & - & $0.00 \pm 3.08$ \\
GT & $7.481 \mu \mathrm{g} / \mathrm{ml}$ & $5.41 \pm 6.59$ \\
RV & $22.44 \mu \mathrm{g} / \mathrm{ml}$ & $14.01 \pm 2.36$ \\
OJ & $29.93 \mu \mathrm{g} / \mathrm{ml}$ & $-7.57 \pm 5.96$ \\
RJ & $0.074 \mu \mathrm{g} / \mathrm{ml}$ & $-4.27 \pm 4.58$ \\
Lemon & $0.074 \mu \mathrm{g} / \mathrm{ml}$ & $-1.83 \pm 3.93$ \\
F2 & $60 \mu \mathrm{g} / \mathrm{ml}$ & $26.31 \pm 4.73$ \\
Cumulative inhibition of lipid production by the ingredients of $\mathrm{F} 2=5.75 \%$ &
\end{tabular}

The synergistic effect of F2 by its ingredients on lipid production by 3T3-L1 adipocytes was determined by ORO assay. The lipid accumulations (expressed as the percentage of control) are presented as means \pm SD of triplicate experiments. GT: Geranium thunbergii; RV: Rhus verniciflua; OJ: Orostachys japonicus; RJ: Royal jelly.

periods is shown in Figure 4. As presented in Table 5, the HFD control group significantly gained body weight compared with that of the normal group. However, weights of mice treated with high dose $(46 \mathrm{mg} / \mathrm{kg})$ of F2 and GC $(200 \mathrm{mg} / \mathrm{kg}$ ) were found to be significantly reduced within 8 weeks in comparison to the HFD control group. The food intake pattern was similar among the HFD fed groups. Food efficiency ratio (FER) for F2 $(46 \mathrm{mg} / \mathrm{kg})$ and GC was found to be lowered in comparison to the HFD control group indicating the lowest food was utilized for weight gain in those groups.

3.7. Effect of F2 on Lipid Excretion. The mice feces were collected before one day of sacrifice for the measurement of lipid content. The feces lipid content represents the excretion of dietary fat without absorption from the alimentary canal. In the current experiment, F2 and GC were found to enhance lipid excretion in feces compared with the HFD (Figure 5). The lipid excretion by F2 was increased in a dosedependent manner. This result suggests that the reduction of body weight in the F2 group might be due to inhibition of lipid absorption in the gastrointestinal tract.

3.8. Effect of F2 on Fasting Blood Glucose. The fasting blood glucose of mice was measured before sacrifice. As shown in Figure 6, the blood glucose was elevated in the HFD control group $(173.17 \pm 9.52 \mathrm{mg} / \mathrm{dL})$ compared to the normal group $(155.00 \pm 8.51 \mathrm{mg} / \mathrm{dL})$. The blood glucose was significantly reduced in F2 treated groups. $23 \mathrm{mg} / \mathrm{kg}$ and $46 \mathrm{mg} / \mathrm{kg}$ treated groups showed blood glucose level of $139.60 \pm 13.52 \mathrm{mg} / \mathrm{dL}$ and $147.80 \pm 17.61 \mathrm{mg} / \mathrm{dL}$, respectively. But the GC treated groups remained nonsignificant with the HFD control. The blood-glucose-lowering effect of F2 may have a beneficial effect on the management of diabetes and its complications.

3.9. Effect of F2 on Organ Weights and Histological Observation. The epididymal white adipose tissue (WAT), liver, kidney, and spleen were isolated and weight was taken in situ. As presented in Table 6, the weights of WAT were increased significantly in the HFD group compared with that in the normal group. However, WAT weight was markedly decreased by F2 in a dose-dependent manner. Moreover, the histological morphology of epididymal WAT and liver was determined by H\&E staining. The histological observation of liver tissue revealed the accumulation of lipid droplets into the liver in the HFD control group. Similarly, the sizes of adipocytes in WAT were enlarged. Treatment with F2 inhibited lipid deposition into the liver and reduced the size of adipocytes in WAT (Figure 7). The diameter of adipocytes in the WAT was significantly reduced with the treatment of F2 and GC in comparison to the HFD control (Figure 8).

\section{Discussion}

Obesity, caused by the over deposition of lipids into WAT, is perceived as a global health risk in present days. Multiple metabolic maladies such as diabetes, cardiovascular diseases, fatty liver disease, mental disorders, and even certain cancers resulting from a complication of obesity are seriously threatening human health $[2,36]$. Secondarily to the dietary restriction and exercise, several drug therapies are also recommended for the management of obesity. However, unexpected adverse effects such as cardiovascular, gastrointestinal, and psychological effects associated with most of the antiobesity drugs limit their use in the general population [7]. Therefore, developing alternative therapies for obesity with minimal adverse effects is warranted. Due to having the aforementioned adverse effect along with high cost and physical dependency by long-term use of the pharmaceutical agents, plant-based remedies are gaining attention globally for the management of obesity and overweight [8]. The present study was designed to develop a novel, safe, and effective herbal formulation for the management of obesity. We developed a polyherbal formulation (F2) by homogeneously mixing of trace amount of royal jelly and lemon juice with ethanol extracts of Orostachys japonicus (OJ), Rhus verniciflua (RV), and Geranium thunbergii (GT). We assessed the antiobesity efficacy of the developed formulation in 3T3-L1 adipocytes and high-fat diet-fed C57BL/6J mice. The F2 was further analyzed using UPLC and quantification was done for its major five marker compounds (astragalin, fustin, fisetin, sulfuretin, and ellagic acid).

Free radicals or reactive oxygen species are generated in the body through multiple mechanisms. Chronic inflammation associated with obesity is one of the major causes of systemic oxidative stress in the body [37], which results in the development of metabolic disorders such as insulin 


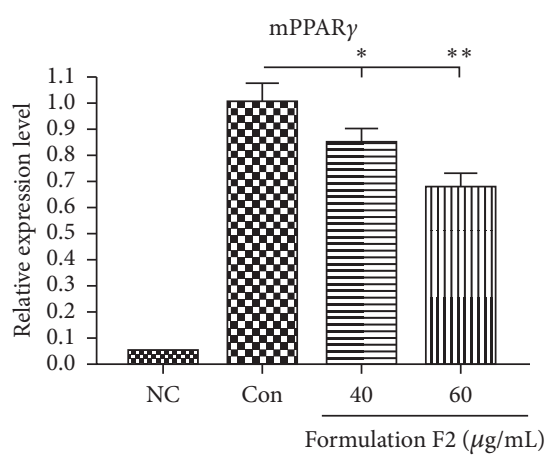

(a)

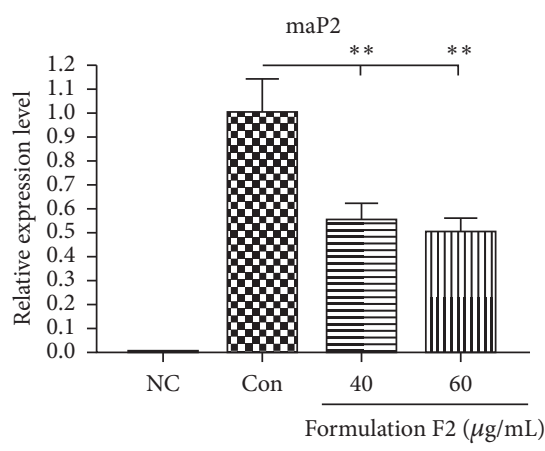

(d)

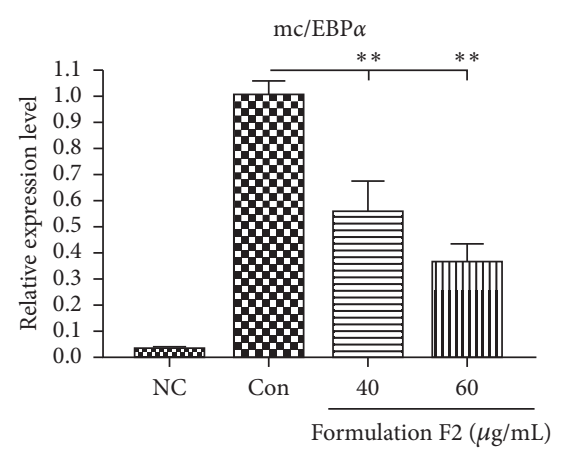

(b)

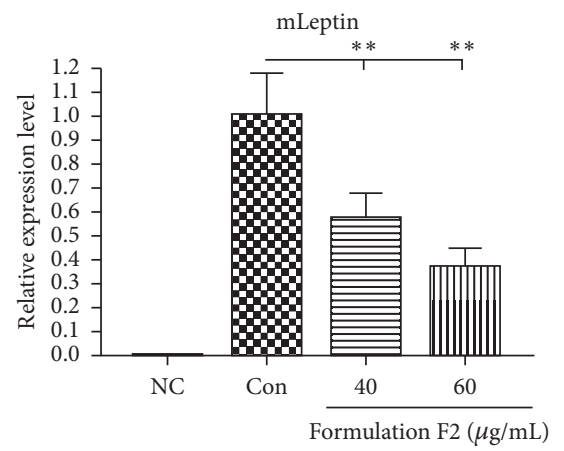

(e)

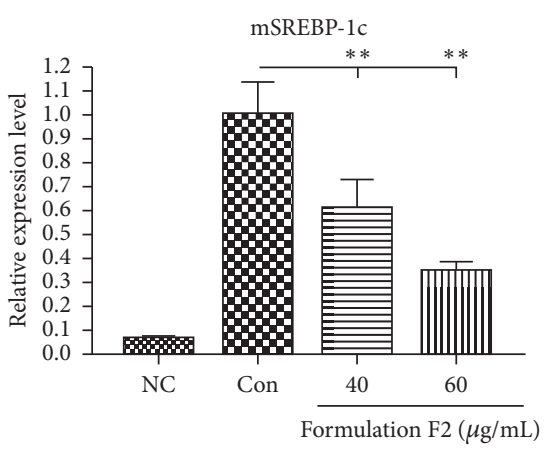

(c)

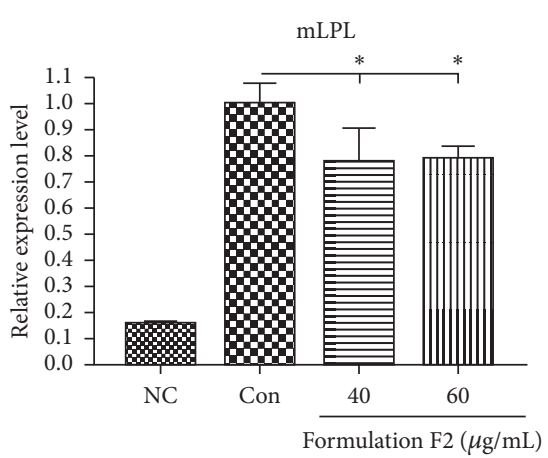

(f)

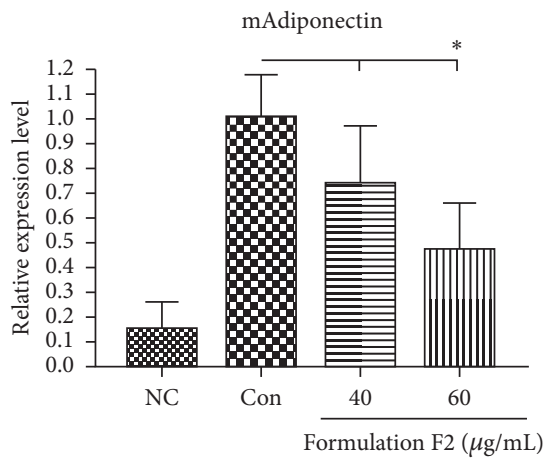

(g)

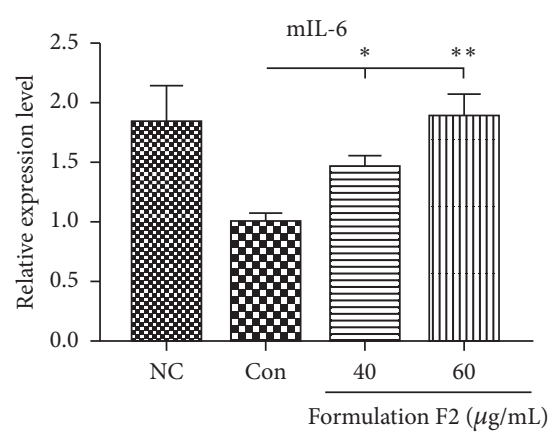

(h)

Figure 3: Effects of F2 on the gene expression level of adipogenic transcription factors during adipocyte differentiation. (a) Peroxisome proliferator-activated receptor gamma (PPAR $\gamma)$, (b) CAAT/enhancer-binding protein alpha (C/EBP $\alpha)$, (c) sterol response element-binding protein-1c (SREBP-1c), (d) adipocyte protein 2 (aP2), (e) leptin, (f) lipoprotein lipase (LPL), (g) adiponectin, and (h) interleukin-6 (IL-6). Each gene's expression levels were quantified and normalized to $\beta$-actin. The data shown are presented as means \pm SD of triplicate experiments. Statistical significance was calculated using one-way ANOVA followed by Dunnett's multiple comparisons test. $* p<0.05$ and $* * p<0.01$ vs. control. NC: negative control (undifferentiated); Con: control (MDI).

resistance, hypertension, asthma, etc. [38]. Herbal remedies with antioxidant potentials can counteract such obesityassociated oxidative damage and prevent comorbidities. The F2 with synergistic antioxidant activity could be a better alternative for preventing and protecting the body from obesity and related complications.

A commitment of stem cell and terminal differentiation of adipocytes into a fat-storing mature adipose cell is a crucial step in obesity [39]. Being a reliable cellular model to study adipogenesis and antiadipogenic activity [40], we selected 3T3-L1 fibroblast cells for the measurement of the antiadipogenic activity of F2. Also, most of the physiology of 3T3-L1 preadipocytes differentiation resembles that in animal tissues making it possible to extrapolate results to humans [41]. The results revealed that F2 treatment significantly reduced the lipid accumulation in 3T3-L1 adipocytes, demonstrating the ability of F2 to inhibit adipocyte differentiation (Figure 2). Previous reports mentioned that the extracts or isolated compounds from O. japonicus [14], $R$. verniciflua $[15,16,26,31]$, and royal jelly [30] had the antiadipogenic effect in 3T3-L1 adipocytes. The present study revealed the synergistic antiadipogenic activity of these ingredients treated even in a very small concentration in formulation F2 (Table 4).

Differentiation of preadipocytes into mature adipocytes is guided by various biochemical regulators such as insulin, 


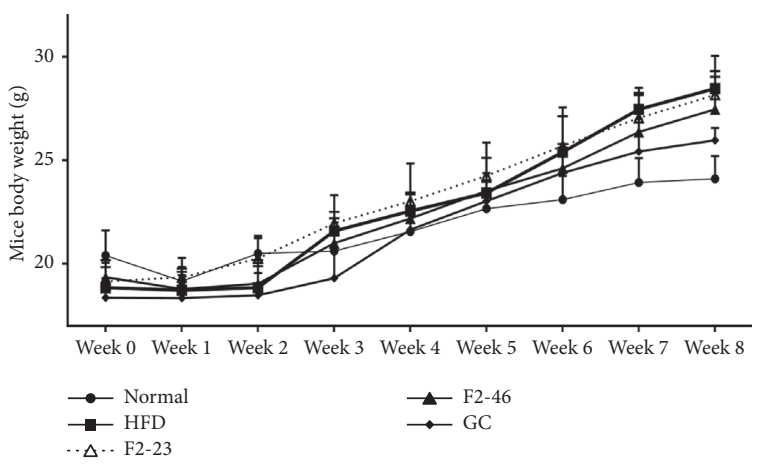

Figure 4: Patterns of body weight gain observed in mice during 8 weeks. Mice body weights were measured every week. Values are expressed as mean $\pm \mathrm{SD}(n=5)$. Normal: standard diet; HFD: high-fat diet control; F2-23: F2 (23 mg/kg); F2-46: F2 (46 mg/kg); GC: Garcinia cambogia $(200 \mathrm{mg} / \mathrm{kg})$.

TABLE 5: Effect of F2 on mice body weight (initial and final), weight gain, food intake, and food efficiency ratio (FER) of different groups during 8 weeks of the experiment.

\begin{tabular}{lccccc}
\hline \multirow{2}{*}{ Groups } & \multicolumn{2}{c}{ Body weight $(\mathrm{g})$} & Weight gain $(\mathrm{g})$ & Food intake $(\mathrm{g} / \mathrm{mice})$ & FER $(\%)$ \\
& Initial & Final & $3.79 \pm 0.68 * * *$ & 180.08 & $2.11 \pm 0.38 * * *$ \\
Normal & $20.40 \pm 1.21$ & $24.10 \pm 1.10$ & $9.61 \pm 0.56$ & 113.3 & $8.48 \pm 0.51$ \\
HFD & $18.85 \pm 0.99$ & $28.46 \pm 0.84$ & $8.99 \pm 1.19$ & 117.85 & $7.63 \pm 1.01$ \\
F2-23 & $19.16 \pm 0.90$ & $28.15 \pm 1.88$ & $8.11 \pm 0.79 *$ & 120.25 & $6.75 \pm 0.65 * *$ \\
F2-46 & $19.35 \pm 0.83$ & $27.46 \pm 1.57$ & $7.586 \pm 0.79 * *$ & 110.23 & $6.88 \pm 0.72 * *$ \\
GC & $18.37 \pm 0.93$ & $25.96 \pm 0.60$ &
\end{tabular}

Food intake and body weight gains were measured every week. Food efficiency ratio (FER) was calculated as follows: FER\% $=$ gained body weight $(\mathrm{g}) \times 100 /$ food intake (g). Results are presented as the mean $\pm \mathrm{SD}(n=5)$. Statistical significance was calculated using one-way ANOVA followed by Dunnett's multiple comparisons test. $* p<0.05, * * p<0.01$, and $* * * p<0.001$ vs. HFD group. Normal: standard diet; HFD: high-fat diet control; F2-23: F2 (23 mg/kg); F2-46: F2 (46 mg/kg); GC: Garcinia cambogia $(200 \mathrm{mg} / \mathrm{kg})$.

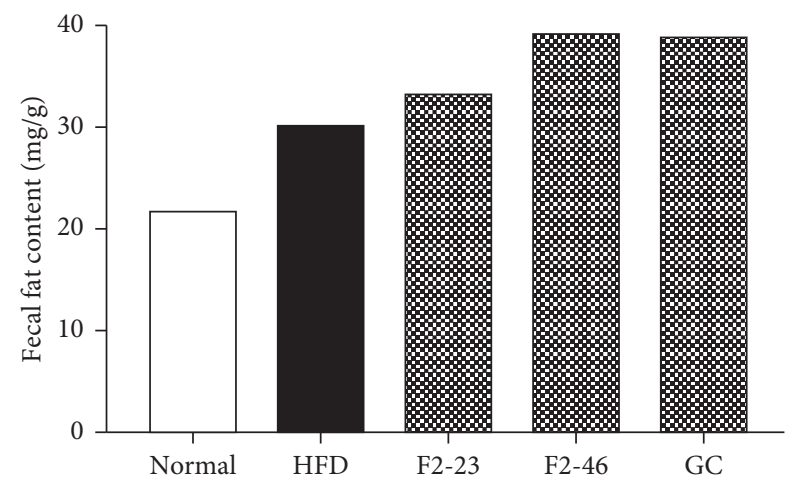

FIGURE 5: Effect of F2 on lipid excretion. Feces were collected from each group cage and lipid contents were measured collectively. The fat content was extracted with methanol-chloroform solvent and presented as percentage of dry stool weight. Normal: standard diet; HFD: high-fat diet control; F2-23: F2 (23 mg/kg); F2-46: F2 (46 mg/ $\mathrm{kg})$; GC: Garcinia cambogia (200 mg/kg).

expressions of adipogenic genes (PPAR $\gamma, \mathrm{C} / \mathrm{EBP} \alpha, \mathrm{SREBP}-$ 1c, aP2, leptin, LPL, FAS, adiponectin, etc.), and accumulations of TG and free fatty acids in cells [39, 42, 43]. Therefore, downregulation of the adipogenic transcription factors may restrict initial as well as terminal differentiation, leading to inhibition of lipid accumulation in adipocytes. In the present study, our observations revealed that the gene expression level of the adipogenic factors was significantly downregulated suggesting the crucial role of $\mathrm{F} 2$ in the

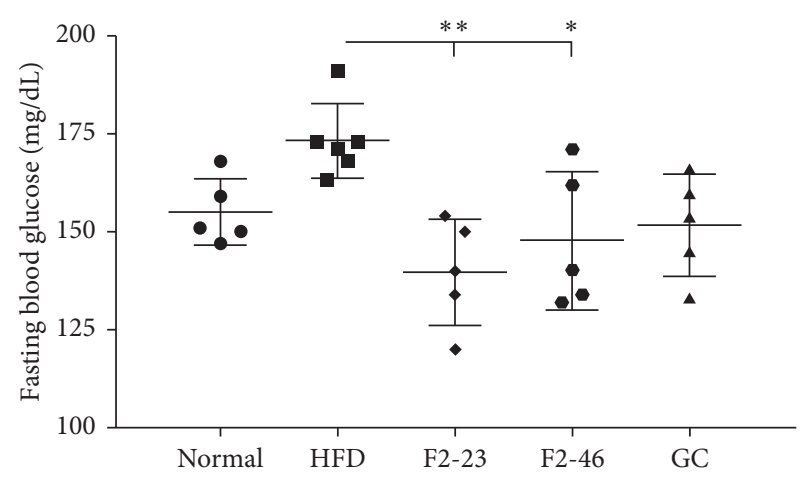

FIgURE 6: Effect of F2 on fasting blood glucose. Mice were kept fasting overnight. The levels of blood glucose were measured before mice sacrifice. Values are expressed as mean $\pm \operatorname{SD}(n=5)$. Statistical significance was calculated using one-way ANOVA followed by Dunnett's multiple comparisons test. $* p<0.05$ and $* * p<0.01$ vs. HFD. Normal: standard diet; HFD: high-fat diet control; F2-23: F2 (23 mg/kg); F2-46: F2 (46 mg/kg); GC: Garcinia cambogia (200 mg/ $\mathrm{kg})$.

restriction of adipogenesis (Figure 3). In another way, it is understood that the expression of pro-inflammatory cytokines like interleukin-6 (IL-6) is greater in preadipocytes than in 3T3-L1 adipocytes [44]. Hence, overexpression on mRNA level of IL-6 in F2 treated adipocytes suggested that the differentiation of 3T3-L1 preadipocyte was inhibited by F2. But the IL-6 expression was downregulated by 
TABLE 6: Effect of F2 on organ weight.

\begin{tabular}{lcccc}
\hline Groups & WAT $(\mathrm{g})$ & Liver $(\mathrm{g})$ & Kidney $(\mathrm{g})$ & Spleen $(\mathrm{mg})$ \\
\hline Normal & $0.46 \pm 0.09 * * *$ & $0.94 \pm 0.05 *$ & $0.29 \pm 0.02$ & $53.17 \pm 5.71$ \\
HFD & $1.38 \pm 0.09$ & $0.82 \pm 0.08$ & $0.28 \pm 0.02$ & $60.59 \pm 8.99$ \\
F2-23 & $1.10 \pm 0.32 *$ & $0.75 \pm 0.07$ & $0.29 \pm 0.02$ & $59.50 \pm 5.32$ \\
F2-46 & $0.75 \pm 0.09 * * *$ & $0.80 \pm 0.06$ & $0.30 \pm 0.03$ & $63.30 \pm 5.68$ \\
GC & $0.92 \pm 0.15 * *$ & $0.77 \pm 0.08$ & $0.30 \pm 0.02$ & $57.88 \pm 10.49$ \\
\hline
\end{tabular}

Results are presented as the mean \pm standard deviation $(n=5)$. Statistical significance was calculated using one-way ANOVA followed by Dunnett's multiple comparisons test. $* p<0.05, * * p<0.01$, and $* * * p<0.001$ vs. HFD group. Normal: standard diet; HFD: high-fat diet control; F2-23: F2 (23 mg/kg); F2-46: F2 (46 mg/kg); GC: Garcinia cambogia $(200 \mathrm{mg} / \mathrm{kg})$.
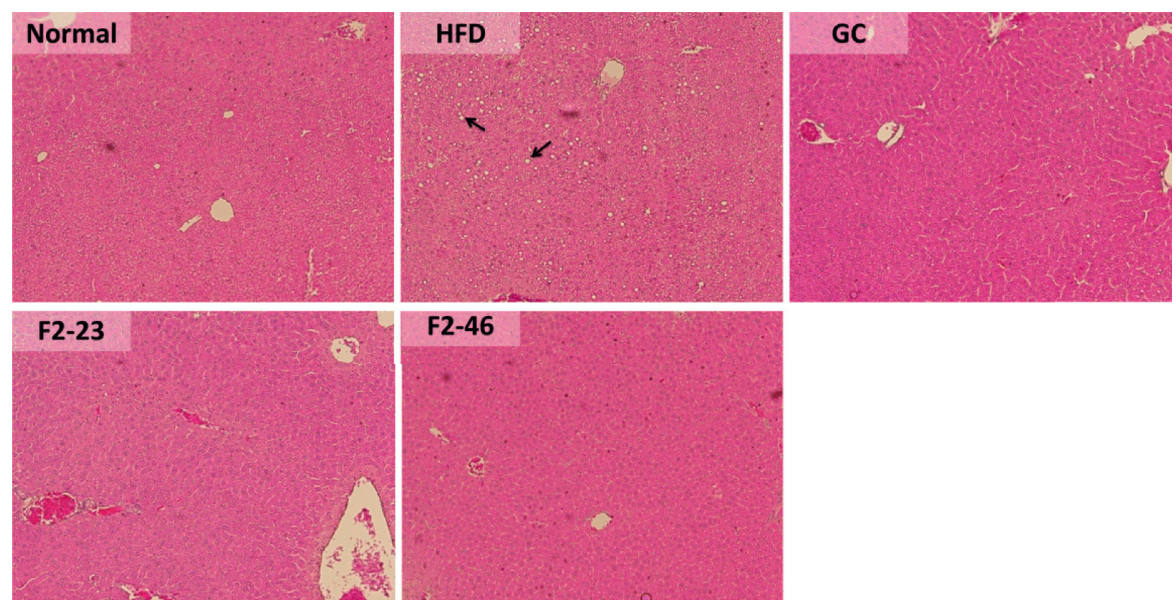

(a)
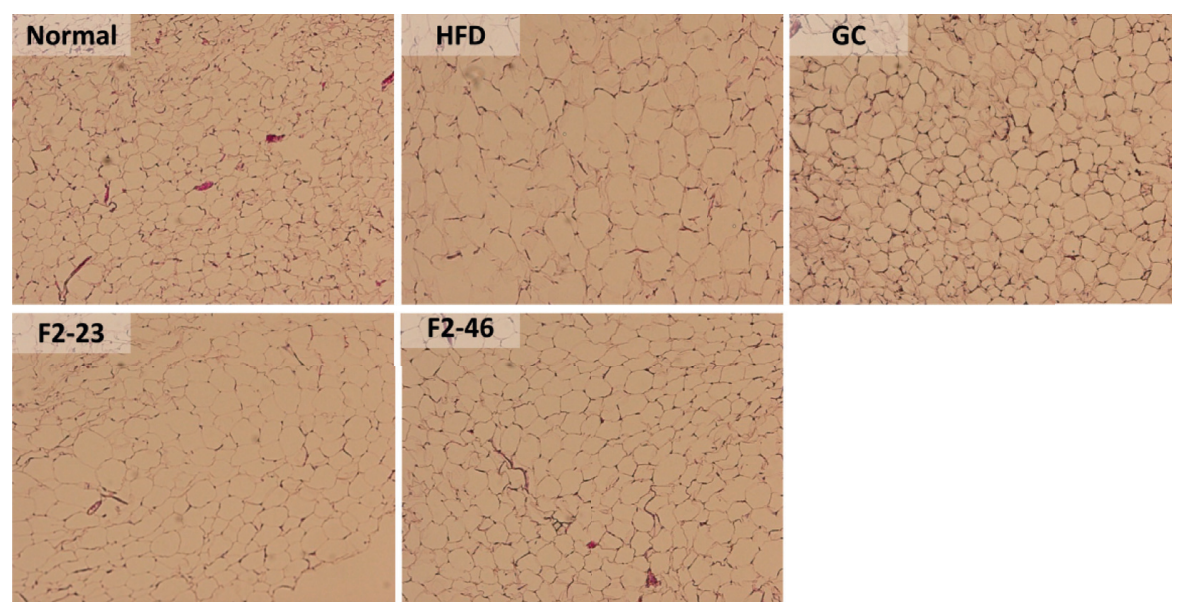

(b)

Figure 7: Effect of F2 on liver and white adipose tissue (WAT) histology. Histological evaluation of (a) liver and (b) WAT was done by H\&E staining (magnification $\times 10$ ). Lipid deposition into the liver and size of adipocytes in WAT were evaluated. The fat droplets deposited in the liver (arrows) are more noticeable in HFD control group mice. Normal: standard diet; HFD: high-fat diet control; F2-23: F2 (23 mg/kg); F246: F2 (46 mg/kg); GC: Garcinia cambogia (200 mg/kg).

O. japonicas in inflammatory human THP-1 cells [45]. Also, $R$. verniciflua decreased the level of hepatic IL-6 in LPS induced rats [46]. Other scientific reports also declared that the F2 ingredients employ potential anti-inflammatory activity [47-50]. In our study, treatment of F2 on LPS induced RAW264.7 macrophages revealed significant inhibition of nitrite production (Supplementary data, Figure S1), indicating the anti-inflammatory response of F2. Hence, the IL-6 expression upregulating effect of F2 in 3T3-L1 adipocyte might only be associated with inhibition of adipocyte differentiation but not inflammatory action. All those observations confirm the potential of the antiadipogenic and antiinflammatory effects of F2.

The exciting outcomes from in vitro experiments encouraged us to conduct an in vivo antiobesity study. In order to confirm the potential of $\mathrm{F} 2$ for preventing obesity, C57BL/ $6 \mathrm{~J}$ mice were fed with a high-fat diet to induce obesity and the F2 was treated simultaneously. A well-accepted 


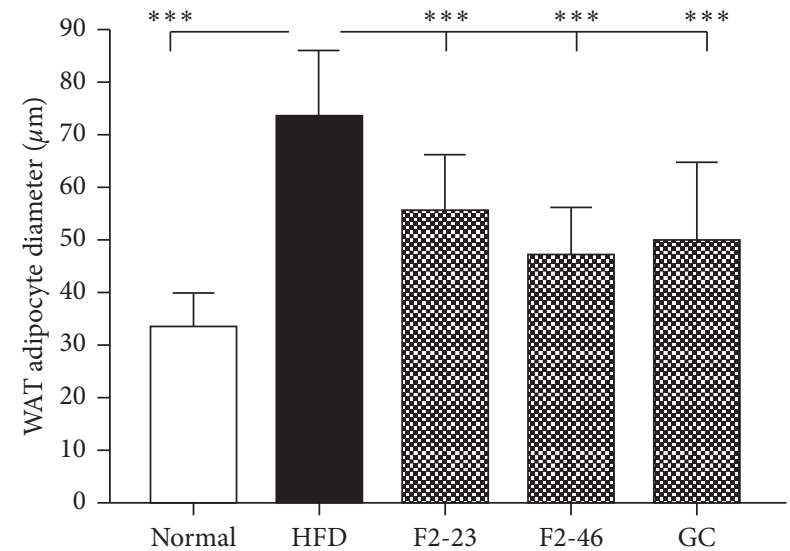

FIGURE 8: Effect of F2 on size of adipocytes in the epididymal white adipose tissue (WAT). The images of WATs from H\&E staining (magnification $\times 10$ ) were analyzed and diameters of the adipocytes were evaluated using ImageJ software. Results are presented as the mean \pm standard deviation. Statistical significance was calculated using one-way ANOVA followed by Dunnett's multiple comparisons test. $* * * p<0.001$ vs. HFD group. Normal: standard diet; HFD: high-fat diet control; F2-23: F2 (23 mg/kg); F2-46: F2 (46 mg/ $\mathrm{kg})$; GC: Garcinia cambogia (200 mg/kg).

antiobesity agent, Garcinia cambogia, was used for standard comparison. Several scientific pieces of the literature demonstrated that a high-fat diet induces obesity and diabetes in animals [51-53]. Obesity in animals can be measured by considering some criteria such as body weight gain, body fat content, and food efficiency [51,54]. The body weight gain has been amplified in the HFD group while F2 slowed down the level of weight gaining. Previous studies revealed that ethyl acetate fraction of O. japonicus and $70 \%$ ethanol extract of $G$. thunbergii showed better antiobesity activity in high-fat diet-induced rodents $[13,19]$. During the process of digestion, dietary fat gets absorbed from the intestine once it is subjected to emulsification with pancreatic lipase [55]. Therefore, alteration of pancreatic lipase may decrease absorption of intestinal fat. Food efficiency ratio (FER) is considered as the relation between total food intake and the amount available for anabolism to increase body weight [56]. The lower FER in F2 treated mice was due to lower weight gain on a similar amount of food consumption. This observation suggests that F2 may impair dietary fat absorption by altering pancreatic lipase. Elevation of lipid excretion in feces by $\mathrm{F} 2$ also supports this finding.

Hyperglycemia or diabetes is one of the major complications of obesity. Previous studies also revealed that the HFD fed mice developed hyperglycemia as well as insulin resistance $[51,57]$. A high-fat diet causes a decrease in glucose transporter, insulin receptors, and glucose metabolism, and reduction in glycogen synthesis in the liver and muscle, which results in elevation of blood glucose [51]. The decreased level of fasting blood glucose by $\mathrm{F} 2$ in comparison to the HFD control indicates that the F2 might have a protecting effect against insulin resistance and related complications. A previous study showed that the $80 \%$ ethanol extract of $O$. japonicus was effective in lowering blood glucose in streptozotocin-induced diabetic rats [10]. Higher blood glucose level is also a consequence of lower storage of glucose in the form of glycogen due to reduction of glycogen synthase in liver and muscle tissue [58]. Besides, the reduction of glycogen synthase accelerates hepatic insulin resistance and liver steatosis, and vice versa. Accumulation of lipid components in the liver activates diacyl glycerol activated protein kinase $(\mathrm{PKC} \varepsilon)$, which further impairs the activation of insulin receptors and insulin-stimulated glycogen synthesis $[59,60]$. Previous studies already exposed the scientific evidence that dietary high fat can lead to liver steatosis which is associated with obesity and liver dysfunction [61]. In our study, feeding a high-fat diet to mice for 8 weeks led to the accumulation of lipid globules in the liver causing liver steatosis in the HFD control group. However, F2 was effective in protecting the liver from steatosis (Figure 7). Obesity is primarily associated with the accumulation of lipids into white adipose tissues [62]. The visceral fat accumulation in epididymal adipocytes in the HFD control groups resulted in a significant increase in the white adipose tissue (WAT) weight. In our observations, F2 significantly reduced the tissue weight (Table 6) as well as adipocytes size (Figure 8) of WAT in dose-dependent manner supporting the effectiveness of $\mathrm{F} 2$ to prevent obesity in $\mathrm{C} 57 \mathrm{BL} / 6 \mathrm{~J}$ mice.

\section{Conclusions}

The present study demonstrated the synergistic antiadipogenic activity of F2 in 3T3-L1 adipocytes. The reduction of adipogenesis might be a result of the downregulation of various transcription factors and adipogenic markers in the adipocytes. Further treatment of F2 in high-fat diet-fed C57BL/6J mice confirmed its preventing effect on obesity and its comorbidities. From the overall results, it may be concluded that the mechanisms of antiobesity activity of F2 include inhibition of adipocyte differentiation, restriction of dietary fat absorption, and reduction of free fatty acids accumulation in tissues. Furthermore, F2 showed potential antioxidant activity, which may alleviate obesity-related oxidative stress. In addition, F2 exhibited potent blood glucose reducing activity in high-fat diet-induced obese mice. Therefore, the novel polyherbal formulation (F2) can be a potential medication for the management of obesity and its comorbidities without adverse effects.

\section{Data Availability}

The data will be made available upon reasonable request to the corresponding author.

\section{Disclosure}

The funding body had no implication in the design of the study, analysis, and interpretation of data, and writing of the manuscript. 


\section{Conflicts of Interest}

The authors declare no conflicts of interest.

\section{Authors' Contributions}

H. J. Jung contributed to conceptualization. P. R. Pandeya, R. Lamichhane, and S. G. Kim contributed to methodology. P. R. Pandeya, G. Lamichhane, and K. H. Lee contributed to formal analysis. P. R. Pandeya, R. Lamichhane, K. H. Lee, and G. Lamichhane contributed to investigation. P. R. Pandeya, G. Lamichhane, and H. J. Jung contributed to data curation. P. R. Pandeya and G. Lamichhane contributed to writing original draft. P. R. Pandeya, H. J. Jung, R. Lamichhane, and G. Lamichhane contributed to review and editing. H. J. Jung and S. G. Kim contributed to project administration and funding acquisition. H. J. Jung contributed to supervision.

\section{Acknowledgments}

The authors give their sincere thanks to the Bio \& Medical Technology Development Program of the National Research Foundation (NRF) and the Korean Government for funding this study. This research was supported and funded by the Bio \& Medical Technology Development Program of the National Research Foundation (NRF) of Korean Government (MSIT) (NRF-2015M3A9A5031098).

\section{Supplementary Materials}

In vitro anti-inflammatory activity of F2 on RAW264.7 macrophage: the Raw264.7 macrophages (ATCC ${ }^{\circledR}$ TIB$71^{\mathrm{TM}}$ ), used to determine the anti-inflammatory efficacy of F2, were purchased from American Type Culture Collection (ATCC). The macrophages were induced by lipopolysaccharide (LPS) and different concentrations of F2 were treated. The absorbance of nitrites produced by LPS induced RAW264.7 macrophages was measured spectrometrically and the amount was calculated using linear regression curve of sodium nitrite standard. The result showed that nitrite production was significantly higher in LPS induced control wells compared to the noninduced control. The treatments of F2 at the concentration of 20,40 , and $80 \mu \mathrm{g} / \mathrm{mL}$ significantly reduced LPS nitrite production. This result suggested that the F2 may exhibit anti-inflammatory activity. (Supplementary Materials)

\section{References}

[1] World Health Organization, Obesity and Overweight, World Health Organization, Geneva, Switzerland, 2020.

[2] T. Ananthakumar, N. R. Jones, L. Hinton, and P. Aveyard, "Clinical encounters about obesity: systematic review of patients' perspectives," Clinical Obesity, vol. 10, no. 1, Article ID e12347, 2020.

[3] UNICEF, WHO, World Bank Group, Levels and Trends in Child Malnutrition in UNICEF/WHO/World Bank Group Joint Child Malnutrition Estimates Key Findings of the 2016 Edition, World Bank, World Health Organization, WorldBankGroup, Washington, DC, USA, 2016.
[4] I. M. Faust, P. R. Johnson, J. S. Stern, and J. Hirsch, "Dietinduced adipocyte number increase in adult rats: a new model of obesity," American Journal of Physiology-Endocrinology and Metabolism, vol. 235, no. 3, p. E279, 1978.

[5] B. J. Klyde and J. Hirsch, "Increased cellular proliferation in adipose tissue of adult rats fed a high-fat diet," Journal of Lipid Research, vol. 20, no. 6, pp. 705-715, 1979.

[6] B. J. Klyde and J. Hirsch, "Isotopic labeling of DNA in rat adipose tissue: evidence for proliferating cells associated with mature adipocytes," Journal of Lipid Research, vol. 20, no. 6, pp. 691-704, 1979.

[7] J. G. Kang and C.-Y. Park, "Anti-obesity drugs: a review about their effects and safety," Diabetes \& Metabolism Journal, vol. 36, no. 1, pp. 13-25, 2012.

[8] K. Sengupta, A. T. Mishra, M. K. Rao, K. V. S. Sarma, A. V. Krishnaraju, and G. Trimurtulu, "Efficacy and tolerability of a novel herbal formulation for weight management in obese subjects: a randomized double blind placebo controlled clinical study," Lipids in Health and Disease, vol. 11, no. 1, p. 122, 2012.

[9] S. Parasuraman, G. Thing, and S. Dhanaraj, "Polyherbal formulation: concept of ayurveda," Pharmacognosy Reviews, vol. 8 , no. 16 , p. $73,2014$.

[10] S. J. Lee, G. F. Zhang, and N. J. Sung, "Hypolipidemic and hypoglycemic effects of Orostachys japonicus A. Berger extracts in streptozotocin-induced diabetic rats," Nutrition Research and Practice, vol. 5, no. 4, pp. 301-307, 2011.

[11] H.-J. Jung, J. Choi, J.-H. Nam, and H.-J. Park, "Anti-ulcerogenic effects of the flavonoid-rich fraction from the extract of Orostachys japonicus in mice," Journal of Medicinal Food, vol. 10, no. 4, pp. 702-706, 2007.

[12] H.-J. Park, H. J. Yang, K. H. Kim, and S. H. Kim, “Aqueous extract of Orostachys japonicus A. Berger exerts immunostimulatory activity in RAW 264.7 macrophages," Journal of Ethnopharmacology, vol. 170, pp. 210-217, 2015.

[13] S. G. Kim, A. Poudel, J. W. Choi et al., "Anti-obesitic effect of Orostachys japonicus in rats model fed a hyperlipidemic diet," Natural Product Sciences, vol. 17, no. 2, pp. 117-122, 2011.

[14] M. Jang, H.-Y. Choi, and G.-H. Kim, "Phenolic components rich ethyl acetate fraction of Orostachys japonicus inhibits lipid accumulation by regulating reactive oxygen species generation in adipogenesis," Journal of Food Biochemistry, vol. 43, no. 8, Article ID e12939, 2019.

[15] N.-J. Song, H.-J. Yoon, K. H. Kim et al., "Butein is a novel antiadipogenic compound," Journal of Lipid Research, vol. 54, no. 5, pp. 1385-1396, 2013.

[16] R. Lamichhane, S.-G. Kim, S. Kang, K.-H. Lee, P. R. Pandeya, and H.-J. Jung, "Exploration of underlying mechanism of anti-adipogenic activity of sulfuretin," Biological and Pharmaceutical Bulletin, vol. 40, no. 9, pp. 1366-1373, 2017.

[17] S.-J. Jeong, J.-G. Park, S. Kim et al., "Extract of Rhus verniciflua stokes protects the diet-induced hyperlipidemia in mice," Archives of Pharmacal Research, vol. 38, no. 11, pp. 2049-2058, 2015.

[18] M.-Y. Song, G.-S. Jeong, K.-B. Kwon et al., "Sulfuretin protects against cytokine-induced $\beta$-cell damage and prevents streptozotocin-induced diabetes," Experimental and Molecular Medicine, vol. 42, no. 9, pp. 628-638, 2010.

[19] Y.-Y. Sung, T. Yoon, W.-K. Yang, S. J. Kim, and H. K. Kim, "Anti-obesity effects of Geranium thunbergii extract via improvement of lipid metabolism in high-fat diet-induced obese mice," Molecular Medicine Reports, vol. 4, no. 6, pp. 1107-1113, 2011. 
[20] T.-H. Kwon, S.-J. Lee, Y.-J. Kim, J.-J. Park, T. Kim, and N.-H. Park, "Anti-inflammatory effect of Geranium thunbergii on lipopolysaccharide-stimulated RAW 264.7 cells," Korean Journal of Food Science and Technology, vol. 48, no. 6, pp. 618-621, 2016.

[21] A.-S. Cho, S.-M. Jeon, M.-J. Kim et al., "Chlorogenic acid exhibits anti-obesity property and improves lipid metabolism in high-fat diet-induced-obese mice," Food and Chemical Toxicology, vol. 48, no. 3, pp. 937-943, 2010.

[22] M. Khazaei, A. Ansarian, and E. Ghanbari, "New findings on biological actions and clinical applications of royal jelly: a review," Journal of Dietary Supplements, vol. 15, no. 5, pp. 757-775, 2017.

[23] A. Petelin, S. Kenig, R. Kopinc, M. Dezelak, M. Cernelic Bizjak, and Z. Jenko Praznikar, "Effects of royal jelly administration on lipid profile, satiety, inflammation, and antioxidant capacity in asymptomatic overweight adults," Evidence-Based Complementary and Alternative Medicine, vol. 2019, Article ID 4969720, 11 pages, 2019.

[24] T. Yoneshiro, R. Kaede, K. Nagaya et al., "Royal jelly ameliorates diet-induced obesity and glucose intolerance by promoting brown adipose tissue thermogenesis in mice," Obesity Research \& Clinical Practice, vol. 12, no. 1, pp. 127137, 2016.

[25] S. Pourmoradian, R. Mahdavi, M. Mobasseri, E. Faramarzi, and M. Mobasseri, "Effects of royal jelly supplementation on body weight and dietary intake in type 2 diabetic females," Health Promotion Perspectives, vol. 2, no. 2, p. 231, 2012.

[26] Y.-A. Rha, M.-S. Choi, and S.-J. Park, "Antioxidant and antiadipogenic effects of fermented Rhus verniciflua," The Korean Journal of Culinary Research, vol. 20, no. 3, pp. 137-147, 2014.

[27] S. R. Cheong, R. Kim, Y. K. Park, S. Baek, S.-H. Yeo, and C. Lee, "Anti-obesity effect of fermented detoxified Rhus verniciflua vinegar supplementation in diet-induced obese rats," Journal of the Korean Society of Food Science and Nutrition, vol. 44, no. 12, pp. 1771-1778, 2015.

[28] S.-G. Kim, J. Choi, H.-J. Park, S.-M. Lee, and H.-J. Jung, “Antihyperlipidemic effects of the flavonoid-rich fraction from the methanol extract of orostachy japonicus in rats," Korean Journal of Pharmacognosy, vol. 40, no. 1, pp. 51-58, 2009.

[29] S.-G. Kim, R. Lamichhane, D. K. Sharma, K.-H. Lee, J. Choi, and H.-J. Jung, "Anti-obesity and anti-hyperlipidemic effects of butanol soluble fraction from methanol extract of Geranium thunbergii in sprague-dawley rats," Korean Journal of Pharmacognosy, vol. 45, no. 1, pp. 69-76, 2014.

[30] P. R. Pandeya, R. Lamichhane, K.-H. Lee et al., "Bioassayguided isolation of active anti-adipogenic compound from royal jelly and the study of possible mechanisms," $B M C$ Complementary and Alternative Medicine, vol. 19, no. 1, p. 33, 2019.

[31] S.-G. Kim, D.-Y. Rhyu, D.-K. Kim et al., "Inhibitory effect of heartwood of Rhus verniciflua stokes on lipid accumulation in 3T3-L1 cells," Korean Journal of Pharmacognosy, vol. 41, no. 1, pp. 21-25, 2010.

[32] S.-J. Jeong, S.-R. Yoo, O.-S. Kim, C.-S. Seo, and H.-K. Shin, "Antioxidant and antiadipogenic activities of galkeun-tang, a traditional Korean herbal formula," Evidence-Based Complementary and Alternative Medicine, vol. 2014, Article ID 763494, 9 pages, 2014.

[33] S. I. Choi, J. S. Lee, S. Lee et al., "Radical scavenging-linked anti-adipogenic activity of Alnus firma extracts," International Journal of Molecular Medicine, vol. 41, no. 1, pp. 119$128,2018$.
[34] K. J. Livak and T. D. Schmittgen, "Analysis of relative gene expression data using real-time quantitative PCR and the 2- $\Delta \Delta$ CT method," Methods, vol. 25, no. 4, pp. 402-408, 2001.

[35] J. Folch, M. Lees, and G. H. S. Stanley, "A simple method for the isolation and purification of total lipides from animal tissues," Journal of Biological Chemistry, vol. 226, no. 1, pp. 497-509, 1957.

[36] R. K. Baboota, M. Bishnoi, P. Ambalam et al., "Functional food ingredients for the management of obesity and associated co-morbidities-a review," Journal of Functional Foods, vol. 5, no. 3, pp. 997-1012, 2013.

[37] G.-S. Liu, E. Chan, M. Higuchi, G. Dusting, and F. Jiang, "Redox mechanisms in regulation of adipocyte differentiation: beyond a general stress response," Cells, vol. 1, no. 4, pp. 976-993, 2012.

[38] P. Manna and S. K. Jain, “Obesity, oxidative stress, adipose tissue dysfunction, and the associated health risks: causes and therapeutic strategies," Metabolic Syndrome and Related Disorders, vol. 13, no. 10, pp. 423-444, 2015.

[39] F. M. Gregoire, "Adipocyte differentiation: from fibroblast to endocrine cell,” Experimental Biology and Medicine, vol. 226, no. 11, pp. 997-1002, 2001.

[40] Y.-C. Tung, P.-H. Hsieh, M.-H. Pan, and C.-T. Ho, "Cellular models for the evaluation of the antiobesity effect of selected phytochemicals from food and herbs," Journal of Food and Drug Analysis, vol. 25, no. 1, pp. 100-110, 2017.

[41] S. P. Poulos, M. V. Dodson, and G. J. Hausman, "Cell line models for differentiation: preadipocytes and adipocytes," Experimental Biology and Medicine, vol. 235, no. 10, pp. 1185-1193, 2010.

[42] D. A. Bernlohr, M. A. Bolanowski, T. J. Kelly, and M. D. Lane, "Evidence for an increase in transcription of specific mRNAs during differentiation of 3T3-L1 preadipocytes," Journal of Biological Chemistry, vol. 260, no. 9, pp. 5563-5567, 1985.

[43] H. Green and O. Kehinde, "Spontaneous heritable changes leading to increased adipose conversion in 3T3 cells," Cell, vol. 7, no. 1, pp. 105-113, 1976.

[44] J. M. Harkins, N. Moustaid-Moussa, Y.-J. Chung et al., "Expression of interleukin-6 is greater in preadipocytes than in adipocytes of 3T3-L1 cells and C57BL/6J and ob/ob mice," The Journal of Nutrition, vol. 134, no. 10, pp. 2673-2677, 2004.

[45] Y.-K. Yoon, H.-J. Woo, and Y. Kim, "Orostachys japonicus inhibits expression of the TLR4, NOD2, iNOS, and COX-2 genes in LPS-stimulated human PMA-differentiated THP-1 cells by inhibiting NF- $\kappa \mathrm{B}$ and MAPK activation," EvidenceBased Complementary and Alternative Medicine, vol. 2015, Article ID 682019, 9 pages, 2015.

[46] J. E. Moon, J.-H. Shin, O. Kwon, and J. Y. Kim, “A standardized extract of Rhus verniciflua Stokes protects wistar rats against lipopolysaccharide-induced acute inflammation," Journal of Medicinal Food, vol. 18, no. 11, pp. 1223-1230, 2015.

[47] H.-J. Choi, H.-J. Choi, M.-J. Park et al., "The inhibitory effects of Geranium thunbergii on interferon- $\gamma$ - and LPS-induced inflammatory responses are mediated by Nrf2 activation," International Journal of Molecular Medicine, vol. 35, no. 5, pp. 1237-1245, 2015.

[48] B.-G. Kim, Y. Song, M.-G. Lee et al., "Macrophages from mice administered Rhus verniciflua Stokes extract show selective anti-inflammatory activity," Nutrients, vol. 10, no. 12, p. 1926, 2018.

[49] J.-D. Lee, J.-E. Huh, Y.-H. Baek, K.-C. Cho, D.-Y. Choi, and D.-S. Park, "The efficacy and mechanism action of RvCSd, a new herbal agent, on immune suppression and cartilage 
protection in a mouse model of rheumatoid arthritis," Journal of Pharmacological Sciences, vol. 109, no. 2, pp. 211-221, 2009.

[50] K. Kohno, I. Okamoto, O. Sano et al., "Royal jelly inhibits the production of proinflammatory cytokines by activated macrophages," Bioscience, Biotechnology, and Biochemistry, vol. 68, no. 1, pp. 138-145, 2004.

[51] N. Hariri and L. Thibault, "High-fat diet-induced obesity in animal models," Nutrition Research Reviews, vol. 23, no. 2, pp. 270-299, 2010.

[52] M. El Ayed, S. Kadri, S. Smine, S. Elkahoui, F. Limam, and E. Aouani, "Protective effects of grape seed and skin extract against high-fat-diet-induced lipotoxicity in rat lung," Lipids in Health and Disease, vol. 16, no. 1, p. 174, 2017.

[53] V. Sunil, N. Shree, M. V. Venkataranganna, R. R. Bhonde, and M. Majumdar, "The anti diabetic and anti obesity effect of Memecylon umbellatum extract in high fat diet induced obese mice," Biomedicine \& Pharmacotherapy, vol. 89, pp. 880-886, 2017.

[54] Q.-Q. Yang, P. K. Suen, C.-Q. Zhang et al., "Improved growth performance, food efficiency, and lysine availability in growing rats fed with lysine-biofortified rice," Scientific Reports, vol. 7, no. 1, pp. 1-11, 2017.

[55] J. R. Senior, "Intestinal absorption of fats," Journal of Lipid Research, vol. 5, no. 4, pp. 495-521, 1964.

[56] E. Bethke, M. Bernreuther, and R. Tallman, "Feed efficiency versus feed conversion ratio--demonstrated on feeding experiments with juvenile cod (Gadus morhua)," SSRN Electronic Journal, 2013.

[57] S. Ikemoto, M. Takahashi, N. Tsunoda, K. Maruyama, H. Itakura, and O. Ezaki, "High-fat diet-induced hyperglycemia and obesity in mice: differential effects of dietary oils," Metabolism, vol. 45, no. 12, pp. 1539-1546, 1996.

[58] A. H. Lichtenstein and U. S. Schwab, "Relationship of dietary fat to glucose metabolism," Atherosclerosis, vol. 150, no. 2, pp. 227-243, 2000.

[59] J. M. Irimia, C. M. Meyer, D. M. Segvich et al., "Lack of liver glycogen causes hepatic insulin resistance and steatosis in mice," Journal of Biological Chemistry, vol. 292, no. 25, pp. 10455-10464, 2017.

[60] V. T. Samuel and G. I. Shulman, "Nonalcoholic fatty liver disease as a nexus of metabolic and hepatic diseases," Cell Metabolism, vol. 27, no. 1, pp. 22-41, 2018.

[61] S. K. Panchal, H. Poudyal, A. Iyer et al., "High-carbohydrate, high-fat diet? Induced metabolic syndrome and cardiovascular remodeling in rats," Journal of Cardiovascular Pharmacology, vol. 57, no. 5, pp. 611-624, 2011.

[62] M. E. F. Vázquez-Vela, N. Torres, and A. R. Tovar, "White adipose tissue as endocrine organ and its role in obesity," Archives of Medical Research, vol. 39, no. 8, pp. 715-728, 2008. 